\title{
Psychiatric Morbidity in a Military General Practice
}

\author{
Capt L S O'Brien, \\ MB, ChB, RAMC \\ ${ }^{*}$ Queen Elizabeth Military Hospital, Woolwich
}

SYNOPSIS: The General Health Questionnaire of Goldberg ${ }^{1,2}$ was used as an indicator of morbidity ${ }^{3}$ in three groups of ${ }^{\circ}$ a Military General Practice in British Army of the Rhine. Group 1 consisted of 299 service and civilian consecutive new $\frac{\overline{\bar{N}}}{\overline{2}}$ attenders at the General Practice. Group 2 of 80 attenders for routine medical examination and Group 3 of a community $\frac{\widehat{\Phi}}{\widetilde{D}}$ sample of $\mathbf{4 4 6}$ soldiers from units in the practice area.

Patients presenting for consultation at the practice were shown to have higher GHQ scores and percentage positive scores than the community sample, which in turn showed higher mean scores than those referred to the practice as $\vec{\circ}$ non-complainants for routine medical examination. Service personnel showed lower mean scores than dependants or: civilians. There were significant differences in scores between groups by rank in soldier attenders, those of junior non- $\vec{\omega}$ commissioned officer rank having lower mean scores and lower percentage high scores than others.

\section{Introduction}

The General Health Questionnaire has been used in a variety of ways to assess psychiatric morbidity in general practice $^{4}$. It has also been used in community studies 5 and in an industrial setting 6 . The authors are unaware of any published study using a military practice.

There are certain differences both favourable and unfavourable between a military general practice in BAOR and an urban practice in the United Kingdom. Dependants of soldiers must endure particular difficulties. These include expatriation, absence of an extended family and the associated support and counselling, mixed nationality marriage, a high proportion of young families, enforced repeated separation from the spouse by exercises, lack of employment opportunities outside the home, and frequent changes of residence. Possible supportive factors might include a clear community identity, a sense of identity or common purpose, and the recognition of all the adverse factors listed above. Soldiers also face the difficulties of expatriation, long working hours, repeated enforced separation from family, and the particular stresses and real potential dangers of a military environment and all that this entails. Potentially favourable conditions include full employment, group identity and a clearly defined position and role in a highly structured society.

\section{Method}

The tool used was the original 60 question form of the General Health Questionnaire of Goldberg. It is a widely used and validated tool in General Practice, and has also been used in community studies. In the latter role there is probably an increased tendency to underestimate the incidence of psychiatric morbidity, in particular chronic disability.

*Now Guys Hospital, London.
The Practice used was a 3,000 patient practice in the Corp rear area of British Army of the Rhine. The Practice population consists of approximately $1,000 \stackrel{\omega}{\omega}$ troops from two very similar major units and one smaller unit from a different corps. The civilian element consisfs of dependents of the above soldiers plus approximatedy 300 civilian employees and their families.

Soldiers of all 3 units participate in frequent exercisgs in which personnel are detached in smaller sub-units arof are deployed at some considerable distance from the homes. Soldiers are also detached to take part in courses and other specialised training. The units contain a high $\overrightarrow{0}$ percentage of technicians and high grade tradesmen.

The study was conducted in three parts, parts 1 an running concurrently.

\section{Part 1}

Consecutive new attenders at one of the two general

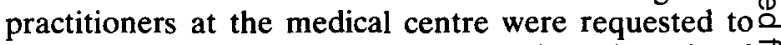
complete the GHQ prior to consultation. Completed $\overrightarrow{0}$ GHQ's were collected at the end of each surgery and 3 scored. They were annotated with the patient's sex, age, rank or status and marital status, their unit, presenting complaint and GHQ score. Three hundred and five $\overline{3}$ questionnaires were issued, and 299 completed and returned, a response rate of $98 \%$.

\section{Part 2}

Servicemen are referred for medical examination at varying intervals. This may be for routine medical $\frac{5}{3}$ assessment according to age, on promotion or leaving the Service, or for assessment of fitness for courses or $\frac{O}{3}$ various types of training. Eighty non-complaining consecutive attenders for medical examinations completed GHQ's. Personal details as in Part 1 were $\frac{}{0}$ recorded.

\section{Part 3}

With the Commanding Officer's consent, and a guarantee of confidentiality, unit personnel were $\omega$ 
circulated with GHQ's, and all ranks requested to complete the form and annotate with their age, rank, sex, marital status and unit.

Due to a number of factors including leave, variable duties, detachment, exercises and courses, not all of the thousand soldiers are available to complete such a questionnaire on one particular date. Four hundred and sixty six usable. returns representing $67 \%$ of the circulated population were received.

No attempt was made to revalidate the GHQ in this study. It seems likely that the result will underestimate the prevalance of minor psychiatric morbidity. Comparison between sub-groups however is possible.

\section{Results}

The percentage high score for presenters at the General Practice was $30.1 \%$. The percentage high scores for community sample of soldiers was $10.76 \%$ and for soldiers attending for routine medical examination was $1.25 \%$. (This using a cut-off score of 12 .) The difference between each of these groups is significant ( $\mathrm{p}=$ less than 0.001 ).

GP attenders (Table 1) the mean GHQ score for all attenders was 9.25 , soldiers having significantly lower scores than civilians $(p=$ less than 0.01$)$. The score for females was higher than that for males, but this did not reach significance.

Scores between sub-groups defined by presenting complaint were not significantly different, although patients presenting with trauma tended to have lower mean scores.

Soldiers of both sexes had lower mean scores than civilians.

Junior NCO's had a lower percentage high scores than all other ranks $(t=3.9, p=$ less than 0.01$)$. Although the two major units were similar in composition and role, there was a lower rate of high scores in unit $B(P=$ less than 0.05).

The percentage high scores for soldiers referred for routine medical examination was $1.25 \%$ (mean score 2.19). There were no significant differences according to rank, unit, sex or marital status between this group and either the presenters or the community survey. The only positive scorer in this group had in fact presented at the practice one week before medical examination with a recurrence of a neurotic depression.

\section{Community Study}

The percentage high scores were $10.54 \%$ (mean score 4.01) there were no significant differences according to sex, marital status, age or unit. There were significan differences according to rank (Table II), Private soldiers having significantly higher scores $(p=$ less than 0.001$)$ This did not seem to be a direct result of age, as the correlation coefficient of score with age $=0.047$.

The sub-group of commissioned officers in the stud was interesting in that of the small group of 24 there wer four positive scorers $(17 \%)$.

Table I

General Practice Presenters

\begin{tabular}{|c|c|c|c|c|c|c|}
\hline Group & All & Soldiers & Civilians & $\begin{array}{c}\text { Soldiers } \\
\text { Unit A }\end{array}$ & $\begin{array}{c}\text { Soldiers } \\
\text { Unit B }\end{array}$ & $\begin{array}{c}\text { Soldiers } \\
\text { Unit C }\end{array}$ \\
\hline $\begin{array}{l}\text { N } \\
\text { Mean Score } \\
\% \text { High Score } \\
\text { Mean Age }\end{array}$ & $\begin{array}{l}299 \\
9.25 \\
30.1 \\
28.7\end{array}$ & $\begin{array}{c}107 \\
7.8 \\
22.42 \\
25.71\end{array}$ & $\begin{array}{c}192 \\
10.42 \\
34.37 \\
30.37\end{array}$ & $\begin{array}{l}50 \\
8.54 \\
28\end{array}$ & $\begin{array}{c}43 \\
5.05 \\
16.2\end{array}$ & $\begin{array}{c}14 \\
8.79 \\
28\end{array}$ \\
\hline Group & All Females & All Males & $\begin{array}{l}\text { Female } \\
\text { Soldiers }\end{array}$ & $\begin{array}{c}\text { Male } \\
\text { Soldiers }\end{array}$ & $\begin{array}{l}\text { Female } \\
\text { Civilian }\end{array}$ & $\begin{array}{c}\text { Male } \\
\text { Civilian }\end{array}$ \\
\hline $\begin{array}{l}\mathrm{N} \\
\text { Mean Score }\end{array}$ & $\begin{array}{c}188 \\
10.2\end{array}$ & $\begin{array}{l}111 \\
7.74\end{array}$ & $\begin{array}{c}13 \\
7.76\end{array}$ & $\begin{array}{c}94 \\
7.085\end{array}$ & $\begin{array}{c}175 \\
10.33\end{array}$ & $\begin{array}{c}17 \\
11.35\end{array}$ \\
\hline
\end{tabular}

Table II

Military Community Study

\begin{tabular}{lccccccccc}
\hline Group & All & Pte & JNCO & JNCO & OFF & Female & Male & Married & Single \\
\hline N & 446 & 157 & 165 & 100 & 24 & 44 & 402 & 268 & 178 \\
Mean Score & 4.00 & 5.4 & 3.2 & 2.95 & 5.2 & 4.6 & 3.53 & 3.39 & 4.0 \\
$\%$ High Score & 10.76 & 15.2 & 7.27 & 8.0 & 16.67 & & & & \\
\hline
\end{tabular}


Scores for those referred for routine medical examination were lower than those in the community study, which were in turn lower than those for presenters at the practice $(p=$ less than 0.001 in each case). Soldiers presenting at the practice had lower scores than civilians $(\mathrm{p}=$ less than 0.01$)$.

\section{Discussion}

Mean GHQ scores and percentage high scores for General Practice attenders are not dissimilar to those found in studies in Manchester General Practices.

Junior NCO's tended to lower scores in the community study and had significantly lower scores when presenting at General Practice. One explanation might be that the relatively secure position of some rank and status and associated privileges without too much executive responsibility might result in a reduction in psychological stresses. An alternative explanation might be that Junior NCO's, conscious and wary of their position and vulnerability, might under-report symptoms. A fear of vulnerability and observation by superiors is certainly thought by some medical officers to be the major reason why commissioned officers rarely present at the General Practice and are therefore not represented in this General Practice Study ${ }^{7}$. The comparatively high scores of commissioned officers in the community study is therefore rather surprising. It raises the interesting question as to whether officers have reported truthfully in the questionnaire, or whether the true incidence of psychological symptomatology is in fact rather higher. Officers in Service units carry a great deal of executive responsibility, almost certainly in excess of that carried by management personnel in civilian organisations.

The difference between the scores for the two major units in the General Practice attenders study is interesting. It is not confirmed in the Community Study. Units A and B are almost exactly similar in their composition and have many similarities in role. One major difference is in location. Unit $A$ is located in an urban area, whereas unit $B$, although only a few miles away, is isolated in the middle of a wood. The difference in scores may be artifactual or may perhaps be related to the fact that Unit $A$ is colocated with the Medical
Centre, whereas Unit B is several miles away. Thus access to the Medical Centre is easier for members of $\varrho$ Unit $A$ and requires less preparation and forethought. $\delta$ Thus members of Unit B may need to be more highly motivated to attend the practice, and different symptoms may produce different degrees of motivation. Although Unit $A$ had a higher presentation rate at the 0 practice than Unit $B$, the difference is not statistically $\frac{}{\sigma}$ significant.

That Private soldiers have higher scores would fit with $\overparen{\varnothing}$ anecdotal observations that very young 17 and 18 year old boys recently arriving in BAOR for their first posting after basic training often show signs of minor? psychological disturbances.

As in previous studies presenters at the General Practice were shown to have higher scores than a community sample. This is not surprising, but the significantly lower scores again for those referred for? routine medical examination might be more so. This $\vec{\omega}$ might be due to the physiological "set" of subjects. Presenters, ie patients, have adopted a complainantos role, and might therefore be more likely to recognis and admit to symptoms than those who have not $ᄋ$ adopted the patient role. This latter group might alspreject symptoms when adopting a role of good health they are being assessed for fitness to undergo training $Q$ a course in which they are interested or which might expected to advance their career.

\section{REFERENCES}

1. GOLDBERG, D. The detection of psychiatric illness questionnaire: London Oxford University Press, 1972.

2. Goldberg, D and Blackwell, B. Psychiatric Illness in General Practice. A detailed study using a new method of case identification. BR Med J 1970; II: 439-443.

3. TARNOPOLSKY, A et al. Validity and uses of a screening questionnaire (GHQ) in the community. Br $J$ Psychiat $\overrightarrow{\bar{O}}$ 1979: 134: 508-515.

4. JohNSTONE, A and Goldberg, D. Psychiatric screening in General Practice. Lancet 1975; I: 605-608.

5. Goldberg, D, Kay, C and Thompson, L. Psychiatric Morbidity in General Practice and the community. Psychol Med 1974; 6: 565-569.

6. BANKS, $M$ et al. The use of the $\mathrm{GHQ}$ as an indicator of mental health in occupational studies. J Occup Psychol 1980; 53: 187-194.

7. WATERS, M. Personal Communication. 1983. 